\title{
EL MOVIMIENTO 5 ESTRELLAS: UTOPÍA DIGITAL Y POPULISMO SIN ADJETIVOS
}

\section{The Five Star Movement: Digital utopia and populism without adjectives}

\author{
ANDREA BETTI \\ Universidad Pontificia Comillas \\ abetti@comillas.edu \\ CARLOS RICO MOTOS \\ Universidad Pontificia Comillas \\ cmrico@comillas.edu \\ Cómo citar/Citation \\ Betti, A. y Rico Motos, C. (2020). \\ El Movimiento 5 Estrellas: utopía digital y populismo sin adjetivos. \\ Revista de Estudios Políticos, 189, 225-257. \\ doi: https://doi.org/10.18042/cepc/rep.189.08
}

\section{Resumen}

La irrupción del Movimiento 5 Estrellas (M5S) ha transformado profundamente el sistema de partidos italiano entre 2008 y 2018. En un fenómeno sin precedentes, un movimiento de protesta surgido en torno a un blog de internet ha conseguido pasar, en pocos años, del espacio virtual de internet a formar parte del Ejecutivo italiano, pactando alternativamente con formaciones situadas a derecha e izquierda en el espectro ideológico. Con el objetivo de clarificar la naturaleza política de este fenómeno sui generis, el presente estudio de caso se apoya en fuentes primarias y secundarias para analizar la ideología, estructura organizativa, medidas programáticas y perfil de los votantes del M5S. Del análisis se concluye que nos encontramos ante un caso poco frecuente de populismo puro, capaz de integrar discursivamente elementos de ideologías contrapuestas para conectar con un sentimiento antipolítico muy extendido entre los votantes italianos, maximizando así su rendimiento electoral. 


\title{
Palabras clave
} Italia.

Populismo; crisis de la representación; antipolítica; internet; partidos políticos;

\begin{abstract}
The irruption of the Five Star Movement (M5S) has deeply transformed the Italian party system. In an unprecedented phenomenon, a protest movement constituted around an internet blog has managed to move, in only eight years, from the virtual space of the Internet to the Italian government, alternately reaching agreements with formations located on the right and the left of the ideological spectrum. In order to clarify the political nature of this sui generis phenomenon, this case study relies on primary and secondary sources to analyze the ideology, organizational structure, programmatic measures and the profile of the M5S's voters. The analysis concludes that the M5S constitutes a rare case of "pure populism", able to discursively integrate elements of conflicting ideologies and to connect with a widespread anti-political sentiment among Italian voters, thus maximizing its electoral performance.
\end{abstract}

\section{Keywords}

Populism; crisis of representation; anti-politics; internet; political parties; Italy. 


\section{SUMARIO}

I. INTRODUCCIÓN. II. LA ANTIPOLIITICA EN ITALIA Y EL SURGIMIENTO DEL M5S: 1. De los orígenes a las elecciones generales de 2013. 2. La difícil transición de la protesta a las instituciones. 3. Victoria electoral y gobierno. III. EL M5S COMO UN POPULISMO «ALLO STATO PURO»: 1. El populismo del M5S. 2. Funcionamiento del M5S: internet y la desintermediación. 3. Perfil del elector. IV. LAS CONTRADICCIONES DEL M5S. V. CONCLUSIÓN. BIBLIOGRAFía.

\section{INTRODUCCIÓN}

El 5 de septiembre de 2019, Giuseppe Conte se convirtió en el primer ministro de Italia por segunda vez en el curso de la XVIII Legislatura, iniciada en marzo de 2018. El Movimiento 5 Estrellas (M5S) formó este nuevo Gobierno gracias a su acuerdo de coalición con el Partido Democrático (PD), de centro-izquierda. Los desencuentros entre el M5S y La Liga de Matteo Salvini habían llevado al fin de la experiencia del Gobierno amarillo-verde (M5S y Liga) y a la creación de un Gobierno amarillo-rojo. Este evento pone de manifiesto la capacidad del M5S para moverse con relativa soltura de un lado al otro del espectro político, formando Gobiernos tanto con partidos de derecha como con partidos de tendencia socialdemócrata o de izquierda. ¿Cómo es posible esta flexibilidad política y programática? La respuesta reside en la naturaleza populista y postideológica de esta formación política.

En su corta existencia, el M5S ha desbordado las categorías convencionales de la ciencia política. Una prueba de ello son las diferentes denominaciones que ha recibido de los estudiosos de las tipologías de partidos: "partido personalista" (Bordignon, 2014), "partido catch-all» (Diamanti, 2014), "partido-movimiento» (Ceccarini y Bordignon, 2016). Algunos estudios han comparado al M5S con los movimientos populistas de izquierda, subrayando las similitudes en cuanto a la crítica a la democracia representativa y la oposición a la casta, pero también las diferencias existentes, como la falta de un proyecto económico claramente intervencionista, presente en movimientos como Podemos o Syriza (Gerbaudo y Screti, 2017). Otros han comparado a esta formación con los populismos de derecha, evidenciando las contradicciones de un movimiento que acuerda formar un grupo 
parlamentario conjunto con el United Kingdom Independence Party (UKIP) en el Parlamento Europeo al tiempo que mantiene una posición ambigua en temas migratorios y de protección de fronteras (Mosca y Tronconi, 2019: 1273-1276; Farinelli y Massetti, 2015: 219-222). Por ello, Andrea Pirro ha definido al M5S como un "populismo polivalente», es decir, un movimiento con capacidad para «asumir posiciones típicas de partidos antiestablishment situadas a ambos extremos del espectro ideológico izquierda-derecha» (2018: 445).

Considerado inicialmente un movimiento de protesta transversal influenciado por ideas progresistas y medioambientalistas, el M5S se parece hoy, con su mayoría relativa en el Parlamento italiano, a un partido catch-all capaz de dirigirse potencialmente a todos los electores «de manera indiferenciada, sin consideraciones y preferencias sociodemográficas, de clase o de territorio" (Corbetta, 2017: 6779). En este sentido, el objetivo de este estudio de caso es profundizar en la naturaleza política del M5S y contextualizar su propuesta como un supuesto, bastante excepcional en el contexto europeo, de lo que el profesor Marco Tarchi denomina "populismo puro" (Tarchi, 2014). Con esta finalidad, la primera sección del trabajo presenta la situación política italiana entre 2008 y 2018 como el contexto temporal que ayuda a entender el surgimiento del M5S y las principales etapas de su recorrido político. En la segunda sección se intentará demostrar la tesis de que el M5S constituye un populismo puro, para lo cual se analizará su ideología, organización, medidas programáticas y el perfil de sus electores. En la tercera sección utilizaremos el marco de la teoría de la democracia para señalar algunas contradicciones y aporías derivadas de su naturaleza populista. Finalmente, el apartado de conclusiones sintetizará las principales ideas del trabajo.

\section{LA ANTIPOLÍTICA EN ITALIA Y EL SURGIMIENTO DEL M5S}

Según Donatella Campus, la antipolítica es una «modalidad de lenguaje utilizada por líderes, partidos y movimientos que se oponen al establishment político denunciando su incapacidad y/o mala fe en el gobierno del Estado y en la gestión de la Administración pública» (2006: 9). Desde este punto de vista, la antipolítica no sería prerrogativa de ninguna ideología en particular, sino que puede encontrarse en diferentes contextos políticos e ideológicos, asumiendo la forma tanto de un rechazo hacia la política como de una protesta activa para modificarla (Mastropaolo, 2005).

$\mathrm{La}$ antipolítica no es un fenómeno reciente en Italia. Ya en los inicios de la primera república (1946-1993) surgieron pequeños movimientos - como el Fronte dell'Uomo Qualunque (Frente del Hombre Cualquiera)— que 
llamaban a defender a los ciudadanos frente a los abusos de las «oligarquías» ideológicas y administrativas (Setta, 2005). Sin embargo, no fue hasta mediados de los años ochenta cuando el resentimiento contra la clase política empezó a propagarse de forma masiva como consecuencia de los casos de corrupción que golpearon duramente al sistema de partidos, dando paso finalmente a la segunda república. Como ha observado Tarchi, a mediados de los ańos noventa Italia se convirtió en la «tierra prometida» del populismo gracias, por una parte, al ascenso de un Silvio Berlusconi que basó su éxito en una crítica implacable de los partidos de la primera república y, por otra parte, a movimientos autonomistas como la Liga Norte. Junto a ello, el fin de la Guerra Fría debilitó la legitimidad de formaciones tradicionales como el Partido Socialista y la Democracia Cristiana, cuyo papel de baluarte frente a un posible avance electoral del Partido Comunista empezó a ser percibido como prescindible. Además, la profundización de la integración europea tras la firma del Tratado de Maastricht acentuó la imagen de una clase política cada vez menos autónoma y necesaria (Orsina, 2019: 52).

En su obra sobre el populismo como un movimiento multidimensional, presente no solo a nivel político, sino también mediático, constitucional, penal y cultural, Manuel Anselmi ha analizado el caso de Italia como «el único país en el mundo en el cual diferentes fuerzas populistas compiten entre sí y en el cual predomina una comunicación política generalizada y caracterizada por un tono y estilo populista" (Anselmi, 2018: 66). Las transformaciones asociadas con el derrumbe de la primera república facilitaron el cambio de una sociedad en la que predominaban los partidos de masas a una sociedad «marcada por la antipolítica, la desconfianza hacia los mecanismos representativos, la glorificación de la sociedad civil y la búsqueda de una validación directa de la acción política». Así, la crisis de los partidos tradicionales favoreció el surgimiento de propuestas «interclasistas y postideológicas» que configuraron una respuesta neopopulista «a los procesos de desintermediación política y económica» (ibid.: 66-67).

Desde el populismo etnorregionalista de la Liga Norte al telepopulismo de Berlusconi, una buena parte de la oferta política italiana se ha configurado alrededor de una mezcla de antipolítica, rechazo hacia los partidos tradicionales y liderazgo personalista. De esta manera, Italia viene a representar un caso bastante peculiar de sistema político en el cual la aparición inicial del populismo ha generado una serie de "populismos antagonistas» $y$ en competición que, sin embargo, comparten una crítica parecida en contra de los políticos de profesión y la glorificación de una supuestamente virtuosa «sociedad civil» (Urbinati, 2019: 69-70). En este sentido, la difusión del populismo en Italia se relaciona con una serie de desarrollos típicos de las sociedades posindustriales, como la antipolítica, la mediatización de la comunicación y las 
campañas electorales, los liderazgos personalistas y la aparición de nuevas formas de participación política (Blokker y Anselmi, 2020).

La crisis económica iniciada en 2008 acentuó estas tendencias, contribuyendo a aumentar las debilidades estructurales de la economía italiana (Bull, 2018) y las desigualdades (Catanzaro, 2018). Las coaliciones de centro-derecha y centro-izquierda que habían gobernado Italia entre 1994 y 2011 fueron identificadas por el electorado como los principales responsables de la situación, aumentando el atractivo de las opciones que prometían acabar con ellas (Caiani y Graziano, 2019). Además, los partidos tradicionales habían fracasado varias veces en sus intentos de crear un sistema político más eficiente (Ceccarini y Bordignon, 2017: 2-5), generando la imagen de una política distante y poco útil para resolver los problemas de los ciudadanos. La caída del apoyo a dichos partidos a partir de 2008 (Pasquino y Valbruzzi, 2013: 467-471) llevó a un aumento de la volatilidad electoral (Tronconi, 2018: 166), facilitando la redefinición de los clivajes electorales tradicionales (izquierda/derecha) y creando las condiciones adecuadas para "politizar el resentimiento». Una generación de nuevos líderes y movimientos supo aprovechar este momento populista (Lanzone y Woods, 2015: 55) y presentar a la opinión pública una nueva división entre un pueblo humillado y una serie de enemigos, identificados principalmente con las élites de centro-derecha y centro-izquierda que se habían alternado en el poder durante la segunda república.

\section{DE LOS ORÍGENES A LAS ELECCIONES GENERALES DE 2013}

Una de las figuras que mejor supo aprovechar esta situación fue Beppe Grillo, un actor cómico que se había hecho particularmente popular a lo largo de los años ochenta y noventa gracias a sus sátiras implacables contra la corrupción. Grillo intentó explotar las nuevas tecnologías, especialmente internet, para difundir sus mensajes de manera masiva y, con ese objetivo, fundó junto al empresario de la comunicación Gianroberto Casaleggio el blog Beppegrillo. com en enero de 2005. Los primeros objetivos del blog eran sobre todo la denuncia de la falta de cultura medioambiental, el retraso tecnológico y los excesos de la sociedad de consumo, ganándose por ello las simpatías de ambientes de izquierda y católico-progresistas (Vignati, 2013: 36). Así, las cinco estrellas del símbolo del movimiento identificaban sus principales propuestas: agua pública, medioambiente, transporte, desarrollo y energías sostenibles (MoVimento 5 Stelle, 2009c). Posteriormente se añadió el tema de la conectividad, centrado en proporcionar a los ciudadanos el acceso libre y gratuito a internet.

Es especialmente en este último ámbito, la conectividad, donde se evidencia la mayor aportación de la Casaleggio Associati, sociedad de 
marketing digital fundada por Casaleggio. Dos videos, producidos en 2007 y 2008, sirvieron para difundir el mensaje de «utopía digital» del empresario, el cual pasará a formar parte del núcleo ideológico del movimiento. En el primer video, llamado Prometeus, se vaticina la progresiva desaparición de los medios de comunicación tradicionales, televisión, radio, libros y periódicos, para ser sustituidos por la web (Casaleggio Associati, 2007). En el segundo, denominado Gaia, se pronostica el surgimiento de una democracia digital directa y transnacional que permitirá a una nueva clase de movimientos sociales debatir y dar solución a los problemas mundiales. En esta visión futurista, las religiones e ideologías serán sustituidas por un nuevo y más fiable «conocimiento colectivo» (Casaleggio Associati, 2008).

Influido por estas ideas, el 8 de septiembre de 2007 Grillo convocó a través de su blog una multitudinaria manifestación en la principal plaza de Bolonia, y recogió 350000 firmas para impulsar una serie de medidas contra la corrupción política. No es hasta octubre de 2009 cuando se crea oficialmente el M5S, formación que comenzó su recorrido electoral obteniendo un puñado de concejales en las regionales de Emilia-Romagna y Piemonte en 2010 y conquistando en 2012 la alcaldía de la ciudad de Parma y la mayoría relativa de la Asamblea Regional de Sicilia (Biorcio y Natale, 2013: 115-133). En estas citas electorales el M5S mantuvo como principio estratégico el rechazo a cualquier alianza con otros partidos o movimientos.

En la campaña de las elecciones generales de 2013 el M5S supo canalizar el sentimiento de protesta existente en el electorado, presentándose como «el enlace ideal entre las dos grandes crisis que habían golpeado el sistema político italiano en los últimos veinte años» (Bordignon y Ceccarini, 2013a: 676), esto es, la crisis económica y la crisis política. Tales fenómenos aumentaron de manera excepcional la volatilidad electoral. Si la volatilidad media en los comicios italianos había sido del 13,5\% entre 1946 y 2013, en 2013 fue del $36,7 \%$, lo que la convirtió en una de las elecciones más volátiles de toda Europa desde la posguerra (Tronconi, 2018: 166). En términos propositivos, el M5S desarrolló un mensaje dirigido a los electores decepcionados tanto a la izquierda como a la derecha. Así, el programa electoral mencionaba, por un lado, la necesidad de luchar contra las grandes concentraciones monopolísticas en el mundo empresarial, cuidar del medioambiente y nacionalizar recursos estratégicos como el agua y la electricidad. Sin embargo, por otro lado se prometían una serie de liberalizaciones para reducir la presencia del Estado en la economía, así como una bajada de impuestos, considerados abusivos para el contribuyente medio. Frente a la crisis del modelo productivo y de los partidos tradicionales, la receta del M5S consistía en una mezcla de proteccionismo económico, democracia directa a través de la red y ruptura de la hegemonía de las coaliciones de centro-derecha y centro-izquierda 
(Corbetta, 2013: 197-214). Con este novedoso mensaje el M5S llegó a ser la opción más votada en 2013.

\section{LA DIFÍCIL TRANSICIÓN DE LA PROTESTA A LAS INSTITUCIONES}

A pesar del excelente resultado cosechado, el rechazo a las alianzas con el resto de partidos desplazó al M5S en favor de un Gobierno de gran coalición resultado del acuerdo entre el PD y una parte del centro-derecha. En esta tesitura, a un genérico riesgo de perder novedad, típico de muchos movimientos populistas que alcanzan las instituciones (Tronconi, 2018: 172), se unían una serie de contradicciones. Desde el punto de vista organizativo, la retórica de la participación ciudadana chocaba con la realidad de un movimiento gestionado de manera plebiscitaria, en el cual Grillo y Casaleggio monopolizaban todas las decisiones importantes. En el plano ideológico, la propuesta de expandir el gasto público para crear una renta mínima universal entraba en contradicción con la prometida rebaja fiscal. Además, en lo relativo a la gestión del fenómeno migratorio - cuestión particularmente sensible en el escenario italiano- la propuesta de los grillinos se mantuvo confusa, debido a la convivencia dentro del M5S de un sector crítico con las políticas de acogida y de otro sector que priorizaba la ayuda humanitaria (Mosca y Tronconi, 2019: 1274). Aunque la orientación como partido catch all permitía al M5S conseguir votos en todos los sectores de población, ello le privaba al mismo tiempo de una clase social de referencia o una ubicación geográfica definida (Colloca y Corbetta, 2015: 195-212).

Estas contradicciones pasaron factura al M5S, que empezó a perder terreno en favor de un renovado PD liderado por Renzi, que se convirtió en primer ministro en febrero de 2014, gracias a un acuerdo de gran coalición con el centro-derecha de Berlusconi, el llamado Pacto del Nazareno. Este acuerdo tuvo el efecto inicial de aumentar el protagonismo del PD que, en las elecciones europeas de 2014 consiguió un $40 \%$ de los votos, casi doblando los resultados del M5S. Grillo se declaró "cansado» y deseoso de reducir su compromiso, motivo por el cual decidió adoptar un rol de "garante» dentro de la formación, al tiempo que acordaba con Casaleggio el nombramiento de cinco figuras conocidas entre los diputados del M5S para conformar un Directorio (Bordignon y Ceccarini, 2015: 465).

A pesar de estas dificultades, a las que se unió en 2016 el fallecimiento de Casaleggio, el M5S consiguió mantenerse como la principal alternativa al PD y al Gobierno de gran coalición, denunciando el Pacto del Nazareno como un ejemplo del intento de la "casta» de perpetuarse en el poder. Las políticas de austeridad llevadas a cabo por el Ejecutivo le permitieron vehicular las insatisfacciones del electorado, llegando a asumir una «fisionomía sociodemográfica 
que coincide cada vez más con la de la población italiana» (Pedrazzani y Pinto, 2017: 3368). La ocasión para votar al M5S en clave antigubernamental se materializó en las elecciones municipales de 2016, en las que los grillinos obtuvieron victorias históricas en las alcaldías de Torino y Roma, ambas gobernadas por el PD (De Rosa y Quattromani, 2019).

Al mismo tiempo, el M5S inició una progresiva transformación hacia un movimiento más segmentado en el que, como se verá más adelante, el principio del "cada uno vale uno» daba paso a reformas internas que hacían los procesos decisionales más verticales. Algunas de las figuras más conocidas en el Parlamento y en los medios de comunicación pasaron a asumir un rol de dirección. Además, se utilizaron las elecciones primarias online para elegir internamente al candidato a primer ministro. Así, a finales de septiembre de 2017 la asamblea de inscritos ratificó al «jefe político» Luigi Di Maio como candidato del M5S para las elecciones generales de 2018.

\section{VICTORIA ELECTORAL Y GOBIERNO}

Las elecciones de 2018 estuvieron marcadas por la gran insatisfacción con las políticas de ajuste presupuestario de los Gobiernos de gran coalición y por la crisis de los partidos tradicionales, PD y Forza Italia, que entraron en una nueva fase de desplome electoral. El PD de Renzi, principal competidor del M5S, había salido muy debilitado de la derrota en el referéndum de 2016 sobre la reforma del sistema político, rechazada por el $60 \%$ del electorado (Ceccarini y Bordignon, 2017). Mientras que el PD y Forza Italia concentraban cerca del $70 \%$ de los votos en 2008 y eran los lideres incontestables de sus respectivas coaliciones, tan solo una década después la suma de sus votos representaba a poco más de un tercio del electorado (Orsina, 2019: 63), con una perdida conjunta de más de cinco millones de electores respecto a las elecciones generales de 2013 (Chiaramonte et al., 2018). En cambio, el M5S pasó del $25 \%$ obtenido en 2013 a ser el primer partido italiano con más del $32 \%$ de los votos. La Liga, que en las europeas de 2014 había obtenido solo el 6\% de los sufragios, superó en esta ocasión el $17 \%$.

En la campaña electoral de 2018 el M5S se centró fundamentalmente en temas económicos prometiendo, al mismo tiempo, medidas sociales como la renta básica universal y una bajada de impuestos para autónomos y pequeñas empresas. Junto a ello, los grillinos moderaron su oposición a la moneda única, eliminando de su programa la propuesta de someter a referéndum popular la permanencia de Italia en el euro. Igualmente, el M5S mantuvo una actitud prudente, hasta la ambigüedad, sobre el tema migratorio (Chiaramonte et al., 2018). Desde el punto de vista geográfico, los grillinos obtuvieron sus mejores resultados en las regiones del centro y del sur, duramente golpeadas por la 
crisis, manteniendo en buena medida su capacidad de representar a los principales sectores del electorado italiano.

La mayor innovación desde el punto de vista estratégico fue el cambio de postura en materia de alianzas postelectorales. Después de dos meses de negociaciones, Di Maio decidió firmar con La Liga un "contrato de gobierno" compuesto de varias medidas legislativas, entre las que destacaban la reducción de impuestos, la creación de una renta mínima garantizada, la posibilidad de anticipar la jubilación y una política de cierre de fronteras para inmigrantes y refugiados. Se configuró así un Gobierno marcadamente populista en el que sus dos líderes, Salvini y Di Maio, ejercían la función de vicepresidentes de Conte, un profesor universitario sin experiencia política. En su discurso de investidura Conte se definió como «el abogado del pueblo», un guiño a la esencia populista de los dos partidos en el Gobierno (Pasquino, 2019: 197). Contrariamente a lo que pudiera pensarse, la decisión de situar como primer ministro a una figura sin procedencia partidista no redujo la tendencia a la personalización de la política en Italia. Como pronto quedó claro, la elección de una figura políticamente débil otorgaba un mayor margen de maniobra a los dos vicepresidentes (Bordignon, 2018). Tras solo un ańo de gobierno, los desacuerdos entre La Liga y el M5S llegaron a un punto de no retorno, propiciando la formación de una mayoría alternativa entre el M5S y el PD que, en septiembre de 2019, volvió a elegir a Conte como primer ministro.

\section{EL M5S COMO UN POPULISMO «ALLO STATO PURO»}

Más allá del carácter polisémico que ha adquirido en el lenguaje cotidiano, buena parte de la literatura especializada conceptualiza al populismo bien como ideología o bien como estrategia política. En el plano ideológico, el populismo plantea una cosmovisión antielitista que divide la sociedad en dos grupos homogéneos y antagónicos: el pueblo, presentado como un sujeto moral colectivo y, por otra parte, una oligarquía corrupta que ha secuestrado la democracia en su propio beneficio (Mudde, 2004: 543). En este sentido, la apelación a una volonté générale indivisible como fuente de legitimación del poder enfrenta al populismo con el pluralismo de la democracia liberal y las instituciones del Estado de derecho, las cuales son a menudo vistas como un freno a la voluntad popular (Canovan, 1999). A su vez, en el plano estratégico, el populismo sería un discurso al servicio de líderes y grupos que, en contextos de crisis y descontento generalizado, buscan maximizar su éxito electoral apelando a una gran mayoría de la población —englobada bajo el significante «nosotros, el pueblo»— frente al statu quo representado por una élite que se dibuja de distintas formas — "la casta», 
«los de arriba», «los bancos»— en función de la conveniencia coyuntural de los populistas (Laclau, 2005).

Antes que excluyentes, ambas interpretaciones se retroalimentan mediante una retórica que actúa simultáneamente como ideología y como estrategia electoral. No obstante, el escaso refinamiento intelectual del populismo lo convierte en una «ideología delgada» (Mudde, 2004; Stanley, 2008) que tiende a mezclarse con ideologías más amplias para enriquecer su corpus teórico y su propuesta programática. En este punto, la conceptualización del M5S como un populismo «en estado puro» (Tarchi, 2014), pone de relieve la originalidad de este caso como un fenómeno populista donde el único elemento permanente es el discurso antipolítico y antielitista, mientras que el recurso al marco ideológico izquierda-derecha deviene contingente ${ }^{1}$. Este carácter postideológico le resulta muy útil al M5S para captar votos a ambos lados del espectro electoral.

Así pues, comprender la naturaleza de un fenómeno sui generis como el M5S requiere prestar atención a dos elementos nucleares a lo largo de su evolución: un discurso populista de carácter antipolítico y una original estructura organizativa en la que internet deja de ser una simple herramienta de dinamización para convertirse en una auténtica reivindicación frente al modelo de democracia representativa. Mientras que el discurso populista asemeja al M5S con otros movimientos de protesta surgidos en Europa a partir de 2008, su original sistema de funcionamiento y el papel conferido a internet como elemento de democratización radical (Natale y Ballatore, 2014: 110) suponen elementos diferenciales.

\section{EL POPULISMO DEL M5S}

Ajustándose a la retórica populista clásica, el discurso del M5S establece una dicotomía absoluta entre el pueblo, concebido como un sujeto moral virtuoso dotado de una voluntad única, y una élite corrupta que destruye la democracia en su propio provecho (Canovan, 1999; Mudde, 2004). En coherencia con este diagnóstico, el relato del M5S apela al eje arribalabajo y afirma

\footnotetext{
Más allá del ámbito del presente estudio, una interesante aportación a la conceptualización del populismo se puede encontrar en el número especial publicado por la revista Partecipazione e Conflitto (Caiani y Padoan, 2020). Apartándose de los estudios politológicos, los colaboradores en este monográfico analizan la dimensión cultural del populismo explorando, por ejemplo, el uso de los medios de comunicación, de la música, de los memes y de la cultura pop en la elaboración de los mensajes populistas.
} 
que el remedio para los males que afligen al pueblo italiano pasa ineludiblemente por abolir cualquier elemento de intermediación para devolverle la soberanía a «la gente» mediante fórmulas de participación directa. Así, Grillo sostiene que el M5S quiere «lograr la democracia directa, la desintermediación entre el Estado y los ciudadanos, la eliminación de los partidos, los referéndums propositivos sin quórum: el ciudadano al poder» (Grillo, 2013a). En este punto, el papel de Grillo encaja con otro de los rasgos normalmente presentes en el populismo, como es la existencia de un liderazgo carismático en el que el líder se comunica directamente con el pueblo (Mudde, 2004: 545).

A su vez, la esencia antipolítica del M5S se manifiesta en la construcción de su identidad en oposición a cualquier rasgo típico de la política convencional. Al igual que otros populismos, esta formación rechaza ser considerada un partido, ya que en su imaginario los políticos profesionales constituyen una élite autorreferencial que solo busca defender sus privilegios. Frente a la partitocracia, el M5S se autodefine en su «no estatuto» como una "no asociación» y «un vehículo de confrontación» (MoVimento 5 Stelle, 2009a: art. 1). La crítica antielitista abarca también a la "casta» de los medios de comunicación, sometidos a los grandes intereses políticos y económicos, e incluso a una institución central de la democracia representativa como el Parlamento ${ }^{2}$ (Bordignon y Ceccarini, 2013b). Así, en su programa electoral de 2009, el M5S afirmaba que «el Parlamento ya no representa a los ciudadanos [...]. La Constitución no se aplica. Los partidos sustituyen la voluntad popular y escapan a su control y juicio» (MoVimento 5 Stelle, 2009b: 3).

Sin apartarse del canon populista, tanto el lenguaje verbal y simbólico como la escenografía del M5S contraponen al «hombre de la calle» frente al establishment representado por sus adversarios. Se apuesta de esta forma por una concepción descriptiva de la representación, entendida como una identidad de características entre representante y representado (Pitkin, 1985). Ya en 2011, anticipándose a la entrada en el Parlamento nacional, el propio Grillo señalaba la diferencia entre los futuros parlamentarios del M5S y el resto de diputados y senadores: «Serán operarios, trabajadores precarios, desempleados, amas de casa, comerciantes, pequeños empresarios, maestros, camioneros, empleados. Gente común sin censura y sin fines de lucro» (Grillo, 2011). La idea de que parecerse a «la gente» legitima para hablar en su nombre

2 Un ejemplo de la naturaleza antipolítica del M5S lo constituyen los vaffanculo days (traducidos literalmente como "días de iros a tomar por culo»), celebrados por primera vez en 2007 en grandes plazas de las ciudades italianas, en los que Grillo reunió a miles de personas para cargar contra el conjunto de la clase política y periodística (Tronconi, 2018: 164). 
se refuerza con medidas simbólicas como obligar a los parlamentarios grillinos a rechazar el tratamiento de "honorable» y sustituirlo por el de "ciudadano» (MoVimento 5 Stelle, 2013). Junto a ello, el aspecto físico y la forma desenfadada de vestir, el lenguaje provocativo y coloquial o la inexperiencia de los cargos electos del M5S se presentan como la garantía de su integridad en oposición a la naturaleza corrupta de la política profesional (Bordignon y Ceccarini, 2013b: 435). Igualmente, las numerosas protestas dentro y fuera del Parlamento italiano - más de treinta episodios contabilizados solo entre 2013 y 2015 - han permitido a los parlamentarios populistas diferenciarse del resto de partidos y ganar visibilidad en los medios (Bordignon y Ceccarini, 2015: 467-468; Tronconi, 2018: 174).

Sin embargo, el discurso y la praxis del M5S incorporan rasgos idiosincráticos que le singularizan dentro de la familia populista. Mientras que otros movimientos populistas solo ven en internet una herramienta para facilitar la participación, en el caso del M5S la red constituye el núcleo de su reivindicación ideológica, en tanto que permite eliminar la intermediación política y comunicativa que caracteriza a la democracia representativa (Musso y Maccaferri, 2018; Bordignon y Ceccarini, 2013b, 2015). En la utopía digital de Grillo y Casaleggio, internet se convierte en un instrumento de democratización al servicio de una sociedad descentralizada y libertaria (Natale y Ballatore, 2014: 112), ya que faculta a los ciudadanos para «realizar un intercambio de opiniones y una confrontación democrática eficiente y eficaz fuera de los lazos asociativos y de partido y sin la mediación de organismos directivos o representativos» (MoVimento 5 Stelle, 2009a: art. 4). Esta herramienta suprime la necesidad de delegar políticamente, «reconociendo a la totalidad de los usuarios de la red el papel de gobierno y dirección normalmente atribuido a unos pocos» (ibid.). En este sentido, los ideólogos del M5S actualizan el mito rousseauniano de una voluntad general que se autodetermina sin necesidad de intermediarios. Como veremos más adelante, el sistema de funcionamiento de esta formación incorpora niveles de participación por vía telemática que desbordan el modelo clásico de los partidos y le acercan a una versión digital de la democracia participativa.

A su vez, frente a la tendencia natural del populismo a buscar apoyo en otras ideologías que le confieran una mayor sofisticación (Mudde, 2004: 544), el populismo del M5S se presenta sin complementos ideológicos y, desde esta perspectiva, constituye una postideología o un metadiscurso vinculado a la posibilidad de una transformación radical de la democracia representativa en favor de una democracia directa (Manucci y Amsler, 2017; Tronconi, 2018). En este punto, el elemento moralista se exacerba hasta eclipsar completamente al programático, de forma que el único programa inmutable en esta formación es el populismo. El resto de issues políticos pueden ser gestionados con 
altas dosis de ambigüedad, según resulte más útil en cada momento. Más allá de la crítica antipolítica y la reivindicación de la democracia directa ${ }^{3}$ no hay necesidad de mantener una coherencia ideológica y, por ello, se pueden utilizar a conveniencia elementos de distintas ideologías. «El M5S no es de derechas ni de izquierdas, está del lado de los ciudadanos. Fieramente populista» (Grillo, 2013b). Como se verá al analizar el perfil de sus electores, la flexibilidad discursiva y estratégica del M5S le permite atraer a votantes de tradiciones políticas alejadas entre sí, pero coincidentes en su rechazo a un enemigo común definido en términos populistas: "casta», "partidos», "Bruselas», «oligarquías financieras», etc.

\section{FUNCIONAMIENTO DEL M5S: INTERNET Y LA DESINTERMEDIACIÓN}

El original funcionamiento del M5S constituye uno de sus principales rasgos distintivos, a la vez que un ejemplo de las posibilidades de participación política abiertas tras la revolución de las tecnologías de la comunicación. La mera existencia de esta organización supone un rechazo al modelo tradicional de partido como «aparato organizado y profesional que actúa como mediador entre ciudadanos e instituciones» (Biorcio y Natale, 2013: 33). Nos encontramos ante un movimiento de protesta organizado en torno a un blog que va adquiriendo progresivamente influencia política offline sin recurrir a una estructura organizativa de partido y sin basar su estrategia comunicativa en el acceso a los medios tradicionales. Así, desde octubre de 2009, el blog de Grillo ha venido funcionando como «sede» del movimiento, canal oficial de difusión de sus planteamientos, espacio de debate y plataforma de votación para la selección de candidatos y la elaboración del programa electoral (MoVimento 5 Stelle, 2009a; Musso y Maccaferri, 2018: 3). Como señala Lorenzo Mosca, el M5S ha incorporado algunas de las tácticas típicas de los nuevos movimientos de protesta, basados en un "personal de coordinación reducido, ninguna sede física, y el uso de internet para fines de organización, toma de decisiones y recogida de fondos» (2014: 40).

En un fenómeno sin precedentes, el salto del M5S desde la protesta online hasta ocupar, entre 2010 y 2018, importantes posiciones institucionales no ha precisado de estructuras intermedias entre el líder y sus seguidores, ni de redes de coordinación entre los grupos de activistas a nivel provincial o regional

3 Con propuestas como permitir referéndums abrogativos y propositivos sin un quorum mínimo, el fortalecimiento de las iniciativas populares o la universalización de internet para que los ciudadanos puedan participar directamente en cualquier reunión pública a través de la red (MoVimento 5 Stelle, 2009b: 3). 
(Biorcio y Sampugnaro, 2019: 2). Los simpatizantes grillinos han ido agrupándose a nivel local siguiendo una dinámica similar a la de un "partido franquicia» (Carthy, 2004: 10; Tronconi, 2018: 170; Bordignon y Ceccarini, 2015: 464), esto es, limitándose a cumplir unas sencillas directrices impuestas por Grillo y Casaleggio como propietarios de la marca y recibiendo a cambio su autorización para concurrir con las siglas del M5S a las distintas convocatorias electorales. En este sentido, el M5S ha funcionado como una metaorganización muy descentralizada, compuesta por una red de pequeńas organizaciones, llamados Meet $U_{p}$, con objetivos particulares a nivel local que se coordinan a nivel central a través del blog (Bordignon y Ceccarini, 2013b: 438). A su vez, con ayuda de un equipo de informáticos, Grillo y Casaleggio han controlado la imagen y dirección política del movimiento, interviniendo ocasionalmente en los grupos locales para retirar el "derecho de uso» de sus símbolos a quienes se apartaban de sus directrices o cuestionaban su autoridad. Llama la atención la casi total ausencia de vínculos formales entre ambas estructuras — blog y grupos locales - las cuales funcionan con total autonomía dentro del respeto a una rígida división del trabajo político (Tronconi, 2018: 170). Junto a ello, hasta la elección en 2017 de Di Maio como jefe político, Grillo ha sido la única cabeza visible del movimiento y el principal elemento de unificación interno y externo en ausencia de estructuras convencionales (Diamanti, 2014: 12).

La organización y el funcionamiento del M5S se presentan por sus líderes como la constatación fáctica de que internet y las nuevas tecnologías posibilitan la participación directa de los ciudadanos, en un claro desafío a los fundamentos de la democracia representativa. Tres son principalmente las dimensiones de funcionamiento en las que el M5S aporta novedades sustanciales.

En primer lugar, el M5S plantea una membresía más cercana al activismo político que a la militancia tradicional partidista. En su documento fundacional se presenta como un movimiento abierto a cualquier ciudadano italiano mayor de 18 años carente de antecedentes penales y que no haya formado parte de otros partidos, añadiendo que la adhesión al mismo no requiere más formalidad que el registro en su sitio web (MoVimento 5 Stelle, 2009a: art. 5). Junto a ello, este documento hace de las primarias online la forma habitual de escoger a los candidatos que concurrirán bajo el símbolo del M5S a las distintas convocatorias electorales (ibid.: art. 7). El objetivo de esta forma de reclutamiento no es otro que la selección de una clase política no profesional y supuestamente más parecida al ciudadano común (Vignati, 2017: 330). En coherencia con ello, la selección de candidatos del M5S al Parlamento italiano de cara a las elecciones de 2013 y 2018 se llevó a cabo a través del voto electrónico de los inscritos en la web del movimiento. De igual forma se celebró en 2017 la elección interna del jefe político del movimiento y candidato a primer ministro. Desconocido por la mayoría de los italianos 
hasta su elección como vicepresidente de la Cámara Baja en 2013, Di Maio era, en realidad, uno de los hombres de confianza de Grillo y Casaleggio y formaba parte de un núcleo de quince diputados a los que el blog había dado especial visibilidad (Iacoboni, 2018: 396). Su nombramiento como jefe político acentuó la tendencia a la personalización y centralización de las decisiones, ejerciendo la prerrogativa de controlar las listas y evaluar la calidad de los potenciales candidatos en las primarias online de 2017 (Biorcio y Natale, 2018: 1251-1277). Por otra parte, el voto online de los inscritos se ha utilizado para ratificar las propuestas de expulsión de los parlamentarios acusados de traicionar los principios del movimiento (MoVimento 5 Stelle, 2013).

En segundo lugar, la idea de que cualquier ciudadano puede influir directamente en la política formal por vía del voto electrónico no queda circunscrita a las primarias internas, sino que se extiende a las decisiones que los electos del M5S deben adoptar tras acceder a las instituciones. La lógica de este planteamiento es que, hasta tanto no sea posible sustituir completamente la representación por formas de participación horizontal, los políticos deben ser considerados empleados temporales de los ciudadanos y sometidos a un estricto control (Grillo, 2005). En consecuencia, los ciudadanos deben poder dar órdenes a sus portavoces a través de internet. Aquí, otra aportación original del M5S es la reintroducción por vía indirecta del mandato imperativo, una figura desterrada de la práctica totalidad de constituciones europeas de postguerra. Para hacerlo posible, los miembros del M5S que se postulan en las primarias internas deben comprometerse previamente a cumplir, en caso de resultar elegidos parlamentarios, el Código de Conducta de la organización, el cual obliga a adherirse a las instrucciones formuladas por los activistas a través de la plataforma online (MoVimento 5 Stelle, 2013). De esta forma, los miembros de base pueden decidir la posición que sus parlamentarios deben mantener ante distintas iniciativas legislativas, temas especialmente controvertidos o que no han sido contemplados en el programa electoral, así como otras decisiones de calado como, por ejemplo, el candidato que debía ser propuesto por los legisladores grillinos en la elección del presidente de la República en 2013 (Biorcio y Sampugnaro, 2019: 6). En aplicación de esta concepción de la representación, a mediados de 2017 habían sido expulsados diecinueve senadores y veintiún diputados acusados de haber traicionado el mandato de las bases (Tronconi, 2018: 173).

Para facilitar aún más la interacción entre los parlamentarios del M5S y los inscritos se lanzó a finales de 2016 la Plataforma Rousseau, un canal independiente para el voto certificado online que permitía a las bases manifestarse sobre las iniciativas legislativas en discusión en las Cámaras regionales, nacionales o en el Parlamento Europeo, teniendo los parlamentarios grillinos que respetar los resultados de estas votaciones. Junto a ello, para cumplir con lo dispuesto en el Código de Conducta, se abrió la posibilidad de que los 
activistas de la formación hiciesen sus propias propuestas legislativas, de forma que aquellas que alcanzasen un nivel de apoyo suficiente en la plataforma fuesen obligatoriamente presentadas en las Cámaras por los parlamentarios del M5S. Todas estas normas pretenden, en síntesis, hacer efectiva la idea central de los líderes del movimiento: internet permite convertir al ciudadano ordinario en legislador (Biorcio y Sampugnaro, 2019: 6).

Finalmente, la tercera gran innovación del M5S consiste en establecer una comunicación directa con sus simpatizantes y con la opinión pública sin recurrir a los medios tradicionales. Como ya se ha señalado, en el relato de esta organización las grandes empresas de la comunicación y sus periodistas forman parte de la élite corrupta, al privar a los ciudadanos de la información necesaria para formarse un juicio político autónomo. Por ello, en tanto que vician el proceso comunicativo de la democracia, los medios deben ser sorteados. Con este objetivo, la estrategia de Grillo y Casaleggio se centró desde el primer momento en centralizar a través del blog todo el flujo comunicativo del M5S con sus simpatizantes, con la opinión pública y con los propios periodistas (Bordignon y Ceccarini, 2015: 463), prohibiendo tajantemente que ningún cargo electo utilizase los medios convencionales $-\mathrm{y}$ especialmente la televisión- para comunicarse con el electorado (MoVimento 5 Stelle, 2013). Conocedores de las dinámicas mediáticas, los ideólogos del M5S confiaban en que la espectacularidad de sus acciones, lo disruptivo de su mensaje y la habilidad comunicativa de Grillo terminarían atrayendo indirectamente la cobertura de los medios tradicionales, los cuales no podrían resistirse a mostrar a su audiencia el show del M5S (Bordignon y Ceccarini, 2015: 464).

Para reforzar esta apuesta, el Código de Conducta obligaba a los parlamentarios grillinos a utilizar la página web del movimiento para informar sobre sus actividades (MoVimento 5 Stelle, 2013). También debían explicar diariamente sus posicionamientos mediante videos publicados en el canal del movimiento en YouTube, una especie de antitelevisión en la que, entre otras iniciativas en pro de la transparencia, se retransmitían en directo negociaciones o reuniones con otras fuerzas políticas. Además de permitir una comunicación directa con la opinión pública, esta estrategia fortalecía el vínculo entre los representantes institucionales del partido y la organización central (Tronconi, 2018: 173).

\section{PERFIL DEL ELECTOR}

El análisis del perfil del votante del M5S ayuda a entender la naturaleza y evolución del apoyo a esta formación. Un estudio sobre los seguidores del M5S en Facebook realizado antes de las elecciones de 2013 (Bartlett et al., 2013) reveló que, inicialmente, sus simpatizantes eran sobre todo hombres $(63 \%)$, mayoritariamente mayores de treinta ańos y con un nivel de estudios 
superior al promedio de la población italiana. La mayoría se declaraba muy pesimista sobre el futuro de Italia. Además, un $83 \%$ de los encuestados afirmaba estar muy poco satisfecho con la democracia italiana, sus partidos y sus instituciones, incluyendo en esta crítica a la Unión Europea, entidad que solo contaba con la confianza del $20 \%$ de los simpatizantes del M5S. Por el contrario, las únicas instituciones consideradas fiables eran internet y las pequeñas empresas. Los temas que más captaban la atención en esta fase eran la situación económica y el desempleo (ibid.: 15-18), junto con la ineficiencia y corrupción del sistema político y la supuesta falta de imparcialidad de los medios de comunicación, a menudo "vistos como una única entidad corrupta» (Bordignon y Ceccarini, 2013b: 433).

En esta primera fase, un $51,5 \%$ de los simpatizantes del M5S procedían del centro-izquierda y de la izquierda, un 27,6 \% del centro-derecha y de la derecha, un 5,1 \% del centro católico, y un 14,3\% de la abstención (Pedrazzani y Pinto, 2013: 106). Las características demográficas confirmaban el éxito del M5S entre los hombres, sobre todo en las franjas de edad de 25-34 y 35-44 años. Cabe destacar aquí que se trataba de ciudadanos cuya socialización política había tenido lugar en dos épocas particularmente problemáticas para Italia, el fin de la primera república y el surgimiento del berlusconismo, ambas caracterizadas por la desaparición de los principales referentes ideológicos y la creciente hostilidad hacia la política profesional. Junto a ello aparecía otra característica que se iba a revelar decisiva para el M5S en los años siguientes: la falta de un perfil social definido. Se trataba de un movimiento sin una ubicación geográfica clara, capaz de obtener votos en todo el territorio y entre todas las categorías profesionales, con la excepción de pensionistas y amas de casa (Pedrazzani y Pinto, 2013: 98). Otra característica clave para el futuro del M5S era la relativa indefinición ideológica de sus seguidores. Mientras que solo el 9,5\% de los votantes de otros partidos afirmaba no reconocerse en ninguna ideología, en el caso del M5S esta afirmación era compartida por un 22,8\% de los encuestados. Además, se trataba del electorado con la mayor "variabilidad de posiciones», es decir, con la mayor presencia tanto de personas que se declaraban de izquierda como de personas que se declaraban de derecha (Pedrazzani y Pinto, 2013: 110-111).

Estas características han llevado a Paolo Natale a identificar cinco diferentes «almas» del M5S antes de 2013. En primer lugar, estarían los «seguidores", aquellos que se acercaron al movimiento atraídos por su propuesta de digitalización de la política. En segundo lugar, «los izquierdistas», aquellos que simpatizaron con el M5S por su crítica en contra del precariado y el deterioro medioambiental y que culpaban a la izquierda tradicional por no haber sabido ponerle freno. Luego vendrían los «racionalistas», es decir, aquellos que no consideraban al M5S como una opción particularmente atractiva, pero al 
mismo tiempo la veían como la única que «podría cambiar las cosas». En cuarto lugar estaría un conjunto de electores procedentes de partidos de derecha y centro-derecha que elegían al M5S por ser "la opción menos mala» entre las disponibles. Por último, los decepcionados del centro-izquierda, que abandonaron al PD por su incapacidad para cumplir sus promesas de reforma del sistema político (Natale, 2014: 30-31).

Las victorias en Parma y en Sicilia en 2012 certificaron la capacidad de los grillinos para atraer también al voto de derecha y hacerse más transversales. Por ello, se ha venido usando la metáfora del «autobús» para definir al M5S como un medio de transporte capaz de atraer a nuevos pasajeros dependiendo del tipo de competición electoral y del tipo de adversario político (Bordignon y Ceccarini, 2013b: 442). Los italianos empezaron a ver al M5S como el instrumento a través del cual era posible castigar, independientemente de la ideología, a quienes ocupaban el poder. El perfil del votante del M5S se acercaba cada vez más al "promedio de los italianos, o, paralelamente, a los electores contiguos al área de la abstención» (Biorcio y Natale, 2013: 65).

El éxito en las generales de 2013 supuso el culmen de esta tendencia. Con un $25 \%$ de los sufragios, el M5S consiguió la mayoría relativa en el Parlamento. El voto a esta formación se distribuyó de manera equitativa en todo el territorio, pudiendo presentarse como un verdadero partido nacional. La tendencia ascendente en las regiones del centro y del sur evidenciaba que esta formación, nacida como un movimiento exitoso sobre todo en el norte y en el centro-norte, era capaz de expandirse por toda la península (Ceccarini y Bordignon, 2016: 142). La distribución regional confirmaba estas características. El M5S se mantenía por encima del $20 \%$ en todas las regiones, excepto en la Lombardia $(19,6 \%)$ y las regiones autónomas caracterizadas por la presencia de partidos étnicos y autonomistas (Tronconi, 2013: 357). No solo era capaz de representar a todos los sectores de la población —a excepción de los mayores de 65 ańos-, sino que eliminaba entre sus electores las diferencias de género, educación y ocupación, consiguiendo resultados parecidos entre hombres y mujeres, más y menos educados, ocupados y no ocupados (Corbetta, 2017: 6646). Tras las elecciones de 2013, el M5S se acercaba al perfil de un partido catch all, capaz de captar votos en todos los segmentos de población.

Esta naturaleza polivalente se aprecia especialmente al analizar la definición que muchos electores del M5S dan de sí mismos. Así, la autoubicación de sus votantes en el espectro político resulta bastante dispersa, siendo capaz de aglutinar a posiciones críticas con las desigualdades socioeconómicas y, a la vez, recelosas de la integración europea y la libre circulación de personas. Esto no significa que el M5S sea asimilable a un partido de centro. Solo un $10 \%$ de sus electores se definía de esta manera en 2017, mientras que en su interior 
seguían conviviendo dos grupos parecidos - y cada vez más en equilibriode electores de centro-izquierda y centro-derecha (20-25\% cada uno), junto a una mayoría relativa $(40 \%)$ que rechazaba las categorías de izquierda y derecha (Ceccarini y Bordignon, 2018: 352-3). El dato más interesante era sin duda la transversalidad de sus apoyos y la gran habilidad para «unir a grupos de ciudadanos con orientaciones ideológicas muy diferentes» (Ceccarini y Bordignon, 2016: 132; Tronconi, 2015: 224).

La búsqueda de la transversalidad se constata también al analizar los sucesivos programas políticos del M5S. Inicialmente, la Carta de Florencia se centraba sobre todo en cuestiones relacionadas con la protección del medioambiente y la gestión pública del transporte y los recursos básicos como el agua (MoVimento 5 Stelle, 2009c). En cambio, en su "Carta a los italianos» pocos días antes de las elecciones de 2013, Grillo proponía una mezcla de medidas afines al electorado de izquierda, como una renta básica universal y la financiación de la escuela pública, y medidas más afines al centro-derecha y la derecha, como la abolición de los impuestos sobre la vivienda y un referéndum sobre la permanencia en el euro (Grillo, 2013c).

Como ha observado Ilvo Diamanti, tras las elecciones de 2013 el M5S consolidó su tendencia a la transversalidad, convirtiéndose en una opción atractiva para una porción cada vez más amplia de electores de derecha y centro-derecha. La crisis del liderazgo de La Liga, salpicada por una serie de escándalos financieros y, por otra parte, el Gobierno de gran coalición entre el PD y el centro-derecha a partir de ese año, aceleraron este proceso. El M5S dejó de ser solo un vehículo de la protesta de izquierdas para convertirse en "un instrumento para oponerse a la izquierda», especialmente en aquellos contextos donde la derecha no tenía muchas opciones de victoria (Diamanti, 2014: 8). Dependiendo del contexto geográfico y del color político del partido incumbent, el M5S se convertía en el vehículo del hartazgo social, por ejemplo en los municipios de Roma y Torino, ambas arrebatadas al PD en 2016.

En definitiva, si en sus comienzos el movimiento grillino fue capaz de converger fundamentalmente con las tendencias del electorado de izquierda y centro-izquierda, entre 2009 y 2013 se transformó en un partido presente en todos los tipos de electorado. En 2012, un $44 \%$ de sus electores procedía de la izquierda o del centro-izquierda, un $21 \%$ del centro-derecha y de la derecha, un $12 \%$ del centro y un $23 \%$ de aquellos que no se definen ideológicamente. Entre 2012 y 2016 se redujo la cuota de votantes procedentes del centro-izquierda y la izquierda (36\%), aumentando la cuota de centristas (16\%), de los que no se definen (26\%), y de los que proceden de la derecha y el centro-derecha (22,5\%) (Pedrazzani y Pinto, 2017: 3421-3452). Estos datos tan inusuales solo se pueden comprender desde la orientación postideológica del M5S, la cual configura un populismo en estado puro. 
Gráfico 1. Preferencias ideológicas de los electores del M5S (\%)

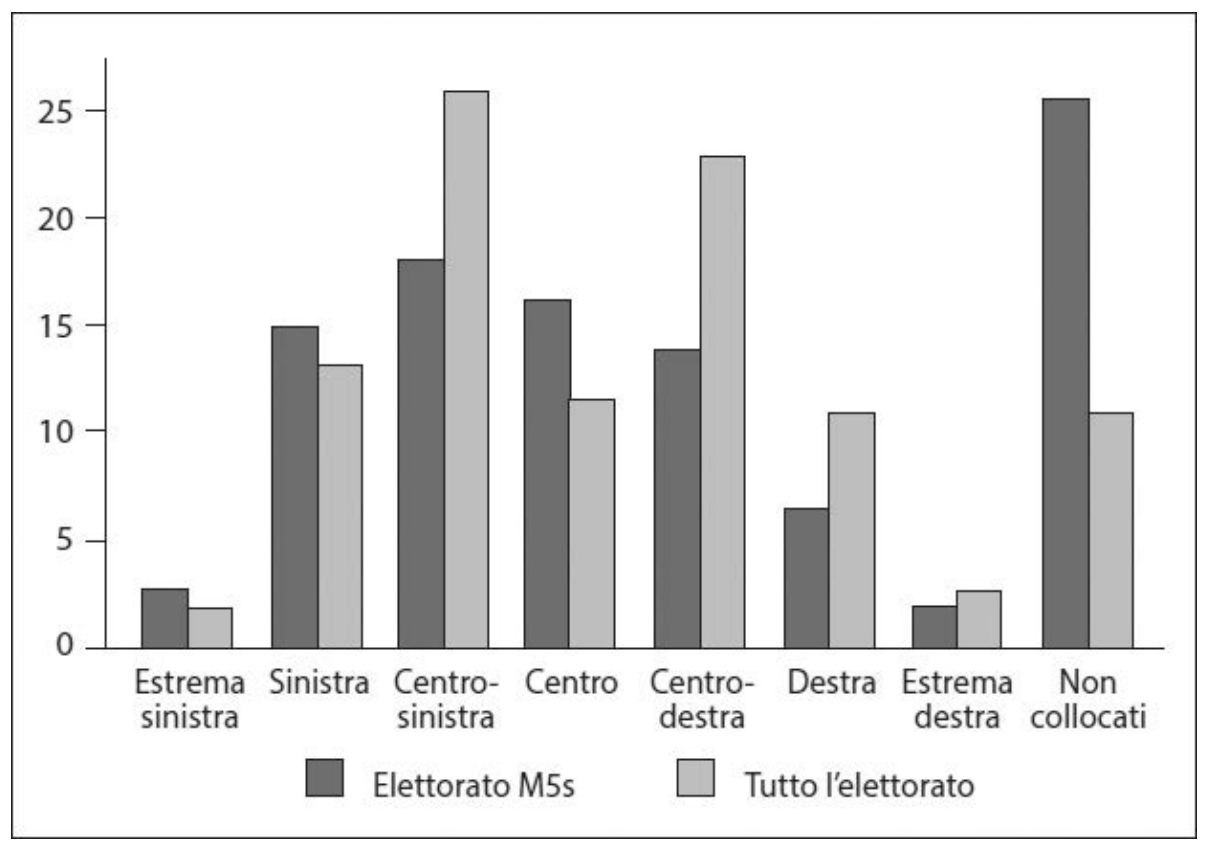

* Pregunta: «Independientemente de su voto en las elecciones, usted personalmente se definiría de: extrema izquierda, izquierda, centroizquierda, centro, centroderecha, derecha, extrema derecha, no sabe, no indica».

Fuente: Pedrazzani y Pinto (2017: 3418).

Finalmente, el programa electoral para las generales de 2018 confirmaba el mensaje «a la izquierda, a la derecha, y hacia fuera» (Ceccarini y Bordignon, 2018: 352). Para atraer al voto de izquierda se prometía una lucha implacable contra la precariedad laboral a través de medidas que implicaban un fuerte gasto público, como la creación de una «renta de ciudadanía» (MoVimento 5 Stelle, 2018a: 2). Para atraer al voto de derecha se proponía una reducción de los impuestos para las empresas y para los autónomos (MoVimento 5 Stelle, 2018a: 4). Finalmente, para empatizar con los sentimientos soberanistas presentes en el país, se hablaba de modificar el "pacto presupuestario» europeo para «recuperar la soberanía estatal que se ha trasladado a los mercados» (MoVimento 5 Stelle, 2018a: 3). Una vez más, el populismo del M5S resulta difícilmente clasificable dentro de las categorías de derecha e izquierda. Por ejemplo, aunque el pueblo no se define en términos de etnia o cultura, algo que suele ocurrir con los populismos de derecha, tampoco se concibe solo en términos de desigualdad social. Intentando alejarse de polémicas que pudieran 
identificarlo demasiado con una u otra ideología, la propuesta del M5S alude «al conjunto de los ciudadanos» (Biorcio y Natale, 2018: 1869).

Las elecciones generales de 2018 premiaron este enfoque. El M5S resultó ser la opción favorita de los italianos, superando holgadamente el $30 \%$ de los votos tanto en la Cámara de los Diputados como en el Senado, mientras que La Liga, otro partido populista de corte derechista, aumentó sus apoyos de manera considerable, superando el $17 \%$. Un nuevo clivaje electoral parecía materializarse en la sociedad: por un lado, un bloque de partidos que desde el centro-derecha hasta la izquierda defendían el proyecto europeísta y, por el otro, un bloque de partidos soberanistas críticos con el proceso de integración europea. Al mismo tiempo podría hablarse de una especie de división del trabajo entre populistas, con La Liga obteniendo sus mejores resultados en las regiones del norte, y el M5S en las del centro y sur del país. Significativamente, en las regiones del norte el M5S jugó un papel de barquero de votos desde el centro-izquierda hacia La Liga, en tanto que hubo un doble flujo de votos que llegaron al M5S desde el PD y que, a su vez, salieron hacia La Liga. En el sur del país, en cambio, el M5S se comportó principalmente como un movimiento catch all (Istituto Cattaneo, 2018: 5).

\section{LAS CONTRADICCIONES DEL M5S}

La contradicción entre el discurso inicial del M5S y su praxis política evidencia los dilemas que acompañan el paso desde la protesta antiinstitucional hasta la acomodación en el sistema. Como explica Davide Vittori (2017: 4), el problema de los populistas es que su lucha por el poder institucional les lleva irremisiblemente a convertirse en parte del establishment político, lo cual choca frontalmente con su discurso redentor. El intento por situarse a la vez dentro y fuera del sistema — denostando la democracia representativa mientras que se participa en el juego electoral- evidencia las aporías de estos movimientos antipolíticos. Así, desdiciéndose de algunos de sus postulados iniciales, el M5S se ha abierto progresivamente a acuerdos y alianzas con partidos que antes calificaba como "casta» (la prohibición de llegar a este tipo de acuerdos desaparece en el Estatuto de 2017), de la misma forma que ha ido admitiendo la participación de sus miembros en programas de televisión y otros medios de comunicación tradicionales (Bordignon y Ceccarini, 2015: 462, 464; MoVimento 5 Stelle, 2017a). En este sentido, el éxito electoral del M5S ha venido acompañado del abandono de algunas de sus reivindicaciones originales, vinculadas a una transformación radical de la política como, por ejemplo, la propuesta de someter a referéndum la pertenencia de Italia al euro (MoVimento 5 Stelle, 2018a). 
La evolución del modelo organizativo de esta formación refleja claramente la tensión entre resistencia y adaptación al sistema. El M5S que nace en 2009 constituye una entidad de facto que pretende, en coherencia con su apuesta por la desintermediación política, ser una asamblea virtual de ciudadanos reunida en internet sin mayor formalización que lo dispuesto en un sencillo «No estatuto» de siete artículos y tres escasas páginas (MoVimento 5 Stelle, 2009a). Sin embargo, la búsqueda de una mayor competitividad electoral tras su derrota en las europeas de 2014 abre la puerta a la creación de un «directorio» de cinco parlamentarios —elegidos por Grillo y Casaleggiodestinado a ejercer un liderazgo complementario al de los fundadores del movimiento, lo cual supone una primera ruptura con el principio de horizontalidad (Tronconi, 2018: 174). Esta dinámica se acentúa en 2017, año en que se acomete una profunda reorganización interna de forma que algunos de los elementos idiosincráticos del movimiento - horizontalidad, antijerarquíadejan paso a fórmulas que le acercan al perfil de un partido convencional (Ceccarini y Bordignon, 2018; Biorcio y Sampugnaro, 2019). Así, el «No estatuto» de 2009 es sustituido por un estatuto más formal que reemplaza el «directorio» por un organigrama especializado compuesto por asamblea, garante, jefe político, comité de garantías, colegio de árbitros y tesorero. El M5S evoluciona hacia una organización dotada de órganos intermedios (MoVimento 5 Stelle, 2017a).

Estos cambios, a los que se añade la aprobación de un nuevo código ético (MoVimento 5 Stelle, 2017b), evidencian el intento de dar mayor institucionalidad a la organización al margen del liderazgo de Grillo, cuyo rol de «garante» le sitúa como "guardián de los valores fundamentales del movimiento» y responsable de la «interpretación auténtica e incuestionable del estatuto", cediendo en cambio las responsabilidades de gestión al jefe político (MoVimento 5 Stelle, 2017a: art. 8). El abandono no declarado del principio del "cada uno vale uno" constata el peso de la "ley de hierro de la oligarquía» (Michels, 1983), que obliga a cualquier organización compleja a burocratizarse y delegar funciones en especialistas para ganar en eficiencia. Como resultado, y sin perjuicio de que el proceso de normalización continúe, el M5S es en la actualidad un experimento político en el que conviven elementos típicos de un movimiento con elementos propios de un partido (Ceccarini y Bordignon, 2018: 360-361).

En línea con lo expuesto, la otra gran contradicción del populismo del M5S viene marcada por el contraste entre un discurso asambleario de tintes libertarios y una práctica decisional extremadamente vertical, centralizada y basada en el liderazgo plebiscitario de sus fundadores. Elementos esenciales como la desintermediación y la horizontalidad en las decisiones de los inscritos resultan desmentidos por el comportamiento de unos líderes que, a lo largo de 
los años, han cancelado votaciones, suspendido o expulsado de la formación a miembros y representantes electos, así como decidido unilateralmente los candidatos en determinadas circunstancias. Así, solo en los dos primeros ańos de presencia del M5S en el Parlamento, cerca de cuarenta parlamentarios abandonaron la formación por desacuerdo con la línea adoptada por Grillo o fueron expulsados por este mediante un post de denuncia en su blog seguido de la ratificación online de los inscritos (Biorcio y Sampugnaro, 2019: 5). Estas decisiones personalistas se producen con escaso respeto al pluralismo y la discrepancia interna y en un contexto de falta de transparencia y accountability en el que no queda claro el rol de Casaleggio Associati —empresa actualmente dirigida por el hijo del difunto Casaleggio-, la cual gestiona los aspectos técnicos de la web oficial y la Plataforma Rousseau hasta el punto de resultar casi indisociable de la estructura del M5S (Tronconi, 2018: 175).

Paradójicamente, la verticalidad y centralización en la toma de decisiones resultan compatibles con el sistema de voto online de los inscritos, en tanto que estos carecen de autonomía para proponer temas: el qué someter a votación y cuándo hacerlo ha sido desde el origen de la formación una prerrogativa de sus líderes (Bordignon y Ceccarini, 2015: 465). El propio Grillo expone con claridad el principio de funcionamiento del M5S: «El garante político propone una oportunidad política, la red expresa su voluntad y los portavoces implementan la decisión de la red» (Grillo, 2017). De esta forma, la promesa de ampliación democrática ha desembocado en la mayoría de los casos en una "oligarquía participativa», en la cual los inscritos son llamados con frecuencia a contribuir vía online a las decisiones del M5S, pero siempre cuando ello sea compatible con las directrices emanadas desde arriba (Caruso, 2017: 599-600; Manucci y Amsler, 2017: 5). Existe la posibilidad de un uso unidireccional top-down de los instrumentos de comunicación, a través de un estricto control sobre los contenidos que debatir y las reglas decisionales (Mosca y Vaccari, 2017: 5983). Por tanto, contrariamente a lo inicialmente proclamado, el funcionamiento del M5S no ha favorecido un acercamiento más democrático a la política sino que, en ausencia de controles internos, ha exacerbado el elitismo propio de los partidos tradicionales. Frente al ideal de una volonté générale expresada autónomamente a través de la red, el M5S se asemeja más a una organización en la que los inscritos se limitan a pronunciarse a favor o en contra de las propuestas lanzadas unilateralmente por los líderes, los cuales actúan como propietarios de la marca (Musso y Maccaferri, 2018: 13, 16).

El modelo del partido franquicia, abordado al explicar el funcionamiento del M5S, ayuda a contextualizar estas dinámicas. Este tipo de partido es más adaptable a las preferencias de los electores, garantiza una "autonomía funcional de los elementos organizativos» $\mathrm{y}$, sobre todo, permite la 
elaboración de estrategias electorales distintas según las circunstancias, consiguiendo el apoyo de electores muy diferentes en un contexto de alta volatilidad (Carthy, 2004: 12). Sin embargo, entre las desventajas está el riesgo —evidente en el caso del M5S — de crear distintas imágenes del partido, en competición entre sí. Además, este modelo genera la contradicción de un liderazgo al mismo tiempo "fuerte y frágil». Los líderes ejercen un poder notable en la gestión de las políticas y la actividad parlamentaria, así como en la determinación de las estrategias electorales nacionales. Sin embargo, también tienen que satisfacer las exigencias de sus electores e inscritos, por una parte, y de unos representantes con diferentes aspiraciones de carrera, por otra parte, lo cual puede generar divisivos debates internos que amenazan la estabilidad y coherencia de la organización (Carthy, 2004: 21).

Buena parte de las contradicciones señaladas se derivan de la confusión conceptual que atraviesa la propuesta democrática del M5S. El populismo de Grillo y Casaleggio tiende a mezclar indistintamente democracia participativa y deliberativa como una alternativa unívoca al sistema representativo. Sin embargo, la propuesta del M5S se aleja radicalmente del modelo deliberativo. $\mathrm{Su}$ apuesta por aumentar la implicación directa de los individuos en la toma de decisiones sirviéndose de internet atribuye virtudes taumatúrgicas a la participación ciudadana al margen de la calidad de la deliberación previa. Por el contrario, el modelo de la democracia deliberativa exige un debate sosegado, público, basado en información objetiva y de calidad, y con un auténtico intercambio de pareceres antes de la toma de decisión (Manin, 1987; Habermas, 1994; Bohman, 2006), lo cual es la antítesis de una participación plebiscitaria basada en la aplicación mecánica de la regla de la mayoría.

Para el populismo del M5S cualquier decisión nacida de la voluntad popular es intrínsecamente correcta. Sin embargo, nada en la lógica de los referéndums y las consultas online garantiza que la decisión resultante sea el fruto de un debate reflexivo con intercambio de argumentos y atención a todos los puntos de vista. Antes bien, plantear las decisiones políticas en términos dicotómicos introduce una tendencia a la polarización que impide encontrar soluciones consensuadas. Como ya se ha señalado, en ausencia de normas precisas, el margen de maniobra del que disponen los líderes del M5S para condicionar el resultado de las consultas internas es enorme (Vittori, 2017: 13). El hecho de que la práctica totalidad de las consultas online hayan concluido con el apoyo de los inscritos a la línea defendida por Grillo y Casaleggio (Bordignon y Ceccarini, 2015: 457) muestra la tendencia plebiscitaria de esta forma de participación. Esta ausencia de debate sustantivo puede darse también en las primarias para la selección de candidatos. Por ejemplo, la elección en 2017 de Di Maio como jefe político con el 83\% del voto de los inscritos se produjo en ausencia de candidatos alternativos reconocibles y sin 
un debate de fondo sobre las alternativas programáticas de cada contendiente (Ceccarini y Bordignon, 2018: 357).

Por otra parte, plantear una dicotomía cerrada entre participación y representación supone desconocer que prácticas como los referéndums y las consultas electrónicas suponen una forma indirecta de representación, en tanto que quienes toman parte en ellas se erigen en representantes de facto de los ausentes (Ruano, 2010). El problema es que esos participantes activos no constituyen una muestra representativa del conjunto del censo, ya que buena parte de los individuos no desean implicarse en ese tipo de consultas y prefieren delegar políticamente (Hibbing y Theiss-Morse, 2002; Musso y Maccaferri, 2018: 14). En el caso del M5S, la baja participación en sus consultasinternasavala esta afirmación. Así, en las primarias de 2017 para elegir al jefe político del movimiento solo participaron 37442 de los cerca de 140000 registrados (Ceccarini y Bordignon, 2018: 357). Una cifra similar, en torno a 39000 inscritos, participó en enero de 2018 para elegir las listas electorales del M5S al Parlamento (MoVimento 5 Stelle, 2018b). Aunque, en principio, esta baja participación podría considerarse un problema interno, el hecho de que el M5S haya recuperado por vía indirecta la práctica del mandato imperativo hace que las posiciones políticas de diputados y senadores elegidos por un amplio número de italianos queden en mano de un pequeño número de inscritos siempre dispuestos a pronunciarse en las consultas online y frecuentemente sesgados hacia las posiciones más radicales. En este sentido, someter el voto de los parlamentarios del M5S a las instrucciones proporcionadas vía online por ese núcleo de activistas supone privarles del derecho a debatir con el resto de representantes sobre el interés general de la nación y, llegado el caso, a cambiar de posición. En este punto resuena la advertencia de un eminente crítico de la pulsión «directista» en la política contemporánea como Giovanni Sartori, quien afirmaba que aplicar la democracia directa sin asegurar previamente una mejora de la calidad de la opinión pública supondría «colocar a la democracia en un campo de minas» (1999: 6).

Finalmente, el populismo puro del M5S trata de ocultar la frecuente inconsistencia de sus planteamientos cuando se ven obligados a pasar del discurso antipolítico a la gestión concreta. La estrategia de difuminar los posicionamientos ideológicos en el eje izquierda/derecha no evita que algunos de sus enfoques socioeconómicos resulten abiertamente contradictorios. Así, como ya se ha señalado, la propuesta de una renta mínima universal implica una expansión del gasto público difícilmente compatible con las promesas de reducción de impuestos para empresas y autónomos lanzadas en la campaña electoral de 2018 (MoVimento 5 Stelle, 2018a: 2-3). Con todo, es en el ámbito de la Unión Europea donde la inconsistencia ideológica del M5S resulta más evidente. De un discurso moderadamente europeísta esta fuerza 
pasó, durante los años más agudos de la crisis económica, a una crítica abierta a las «élites de Bruselas» por robar la soberanía al pueblo italiano. Sin embargo, el análisis de las posiciones de esta formación en temas tan relevantes como la política exterior y de seguridad, inmigración, empleo y asuntos sociales o política medioambiental, entre otros, muestra que su euroescepticismo es más bien estratégico y orientado a la competición en clave doméstica. Un dato resulta esclarecedor en este sentido: en los temas mencionados, el M5S tiende a votar en el mismo sentido que los partidos europeístas y en contra de las posiciones del eurófobo UKIP, su principal socio en el grupo parlamentario Europa de la Libertad y la Democracia Directa (Franzosi, Marone y Salvati, 2015: 123). Este dato se une a la errática política de alianzas de los grillinos en el Parlamento Europeo, donde solicitaron incorporarse en 2017 al grupo de los verdes y, ante el rechazo de estos, al grupo de los liberales, también sin éxito. Además, en julio de 2019, los diputados del M5S votaron a favor de la europeísta Ursula von der Leyen, representante del Partido Popular Europeo, como presidenta de la Comisión Europea, resultando decisivos para su elección.

\section{CONCLUSIÓN}

El nacimiento y auge del M5S no puede entenderse desconectado de la profunda crisis política y económica que, a lo largo de la última década, ha sacudido con fuerza los cimientos del proyecto europeo. En dicho periodo, los cleavages sociales y políticos que conferían estabilidad a los sistemas de partidos han ido dando paso, especialmente en el sur de Europa, a una nueva división en torno al eje «incluidos y excluidos de los beneficios de la globalización» (Morlino y Raniolo, 2018: 178-180). Este debate situaría, en un lado, a las élites políticas y económicas de corte liberal, interesadas en aumentar la apertura y la integración entre las sociedades europeas y, en el otro lado, a aquellos ciudadanos que encuentran su principal fuente de identidad en la pertenencia a un lugar concreto y, por ello, se sienten amenazados por las dinámicas de integración global (Goodhart, 2017). En este contexto, el declive de los partidos tradicionales corre en paralelo al surgimiento de movimientos populistas capaces de conectar con los "perdedores económicos y culturales» de la globalización (Corbetta et al., 2018) y desencadenar encendidos debates sobre los costes y beneficios de la internacionalización del Estado y los riesgos de la desconexión entre los centros de decisión y las demandas populares (Chryssogelos, 2018). Se trata de debates que superan las fracturas ideológicas clásicas y consiguen crear divisiones dentro de los partidos tradicionales. 
El M5S habría sido especialmente habilidoso a la hora de captar la fuerza de estas nuevas líneas de fractura social y política. Pese a su naturaleza cambiante, esta formación ha conseguido mantener un núcleo ideológico inalterable en torno al populismo antipolítico, una corriente más arraigada en Italia que en otros países de su entorno. La fidelidad a esta delgada ideología populista ha permitido al M5S combinar, sin apenas penalización, elementos propios de la izquierda radical, como el ecologismo y el radicalismo democrático, con otros propios de la extrema derecha como el nativismo o el euroescepticismo. Este carácter camaleónico constituye un elemento idiosincrático que hace del M5S un posible precursor de futuras tendencias del populismo, en su afán por maximizar el apoyo electoral bajo la fórmula del partido catch-all.

En relación con lo expuesto, el presente trabajo ha caracterizado al M5S como un fenómeno poco frecuente de populismo «en estado puro» (Tarchi, 2014). En respaldo de esta tesis, el análisis se ha centrado en la ideología de esta formación, que formula una crítica radical a los mecanismos de intermediación política y comunicativa de la democracia representativa; su organización, que configura un partido basado en la desintermediación digital y la relación directa entre los ciudadanos y sus portavoces, y finalmente, en el perfil de sus electores, muchos de los cuales pueden ser catalogados como "perdedores cosmopolitas» que han visto sus expectativas frustradas por la crisis económica y desean recuperar el control sobre procesos que perciben fuera de su alcance (Ceccarini, 2018). En este punto, aunque comparte con el populismo canónico propuestas como fomentar el uso de las consultas online, la apuesta del M5S va mucho más allá y hace de la participación digital el eje de su modelo de democracia directa. En este sentido, el M5S promueve un «giro digital» que inaugura una nueva fase en la relación del populismo con la democracia (Pirro, 2018: 10). Nadie como este partido para ilustrar las posibilidades abiertas por las nuevas tecnologías de la comunicación, así como los dilemas que estas plantean a la democracia representativa.

$\mathrm{Y}$, sin embargo, es precisamente en la incapacidad de resolver constructivamente tales dilemas donde se aprecia el carácter problemático del populismo del M5S. Así, la promesa de una democracia más auténtica contrasta poderosamente con una gestión plebiscitaria y vertical de las decisiones internas de la formación. Igualmente, resulta dudoso que un electorado tan heterogéneo como el que ha venido respaldando la retórica del M5S continúe pasando por alto sine die sus inconsistencias ideológicas y programáticas. En este sentido, la llegada de este partido al Gobierno en 2018 marca un punto de inflexión, al hacer más patentes las contradicciones que rodean su discurso populista. Desde el poder ejecutivo se ha hecho más difícil explotar la retórica pueblo-élite, tan eficaz para ganar elecciones. Junto a ello, la acomodación al sistema ha obligado a esta formación a renunciar a muchas de sus propuestas iniciales, con el riesgo 
creciente de decepcionar a quienes creyeron en su promesa de redención política. La inesperada dimisión de Di Maio como jefe político del movimiento en enero de 2020, unida a la notable caída de las expectativas electorales tras el acuerdo de Gobierno con el PD, serían una prueba adicional del desgaste que para el populismo supone pasar de la calle a las instituciones.

\section{BIBLIOGRAFÍA}

Anselmi, M. (2018). Populism: An Introduction. London: Routledge.

Bartlett, J., Froio, C., Littler, M. y Mcdonnell, D. (2013). New Political Actors in Europe: Beppe Grillo and the M5S. London: Demos.

Biorcio, R. y Natale, P. (2013). Politica a 5 stelle. Idee, storia e strategie del movimiento di Grillo. Milano: Feltrinelli. Disponible en: https://doi.org/10.1080/23248823.2013.809191. (2018). Il Movimento 5 Stelle: Dalla Protesta al Governo. Milano: Mimesis.

Biorcio, R. y Sampugnaro, R. (2019). Introduction: The Five-star Movement from the street to local and national institutions. Contemporary Italian Politics, 11 (1), 5-14. Disponible en: https://doi.org/10.1080/23248823.2019.1576997.

Blokker, P. y Anselmi, M. (eds.) (2020). Multiple populisms. Italy as democracy's mirror. London: Routledge. Disponible en: https://doi.org/10.4324/9781351115742.

Bohman, J. (2006). Deliberative Democracy and the Epistemic Benefits of Diversity. Episteme, 3 (3), 175-191. Disponible en: https://doi.org/10.3366/epi.2006.3.3.175.

Bordignon, F. (2014). Il Partito del capo. Da Berlusconi a Renzi. Rimini: Maggioli.

- (2018). Ecco a voi il vice-presidenzialismo. Il Mattino [blog], 24-06-2018. Disponible en: https://bit.ly/3fQ67SV.

- y Ceccarini, L. (2013a). The 5 Star People and the Unconvential Parliament. Romanian Political Science Review, 13 (4), 675-92.

- y Ceccarini, L. (2013b). Five Stars and a Cricket. Beppe Grillo Shakes Italian Politics. South European Society and Politics, 18 (4), 427-449. Disponible en: https://doi.org/10. 1080/13608746.2013.775720.

- y Ceccarini, L. (2015). The Five-Star Movement: A hybrid actor in the net of state institutions. Journal of Modern Italian Studies, 20 (4), 454-473. Disponible en: https://doi. org/10.1080/1354571X.2015.1066112.

Bull, M. J. (2018). In the Eye of the Storm: The Italian Economy and the Eurozone Crisis. South European Society and Politics, 23 (1), 13-28. Disponible en: https://doi.org/10.10 80/13608746.2018.1433477.

Caiani, M. y Graziano, P. (2019). Understanding Varieties of Populism in times of crisis. West European Politics, 42 (6), 1141-1158. Disponible en: https://doi.org/10.1080/0140238 2.2019.1598062.

Caiani, M. y Padoan, E. (eds.) (2020). The Cultural Side of Populism. Partecipazione e Conflitto, 13 (1), 1-336.

Campus, D. (2006). L'Antipolitica al governo: De Gaulle, Reagan, Berlusconi. Bologna: Il Mulino. 
Canovan, M. (1999). Trust the People! Populism and the Two Faces of Democracy. Political Studies, 47, 2-16. Disponible en: https://doi.org/10.1111/1467-9248.00184.

Caruso, L. (2017). Digital Capitalism and the End of Politics: The Case of the Italian Five Star Movement. Politics and Society, 45 (4), 585-609. Disponible en: https://doi. org/10.1177/0032329217735841.

Carthy, K. R. (2004). Parties as Franchise Systems: The Stratarchical Organization Imperative. Party Politics, 10 (1), 5-24. Disponible en: https://doi.org/10.1177/1354068804039118.

Casaleggio Associati. (2007). Prometeus: La Rivoluzione dei Media. Disponible en: https:// www.youtube.com/watch?v=HsJLRX-nK4w.

- (2008). Gaia: The Future of Politics. Disponible en: https://www.youtube.com/watch?$\mathrm{v}=\mathrm{sV} 8 \mathrm{MwBXmewU}$.

Catanzaro, R. (2018). After and Beyond Amoral Familism: The Impact of the Economic Crisis on Social Capital Italian-style. South European Society and Politics, 23 (1), 47-62. Disponible en: https://doi.org/10.1080/13608746.2018.1435386.

Ceccarini, L. (2018). Un nuovo cleavage? I perdenti e i vincenti (della globalizzazione). En F. Bordignon, L. Ceccarini e I. Diamanti (eds.). Le divergenze parallele. LItalia: Dal voto devoto al voto liquido (pp. 3291-3723). Bari: Laterza.

— y Bordignon, F. (2016). The five stars continue to shine: the consolidation of Grillo's 'movement party' in Italy. Contemporary Italian Politics, 8 (2), 131-159. Disponible en: https://doi.org/10.1080/23248823.2016.1202667.

- y Bordignon, F. (2017). Referendum on Renzi: The 2016 Vote on the Italian Constitutional Revision. South European Society and Politics, 22 (3), 281-302. Disponible en: https://doi.org/10.1080/13608746.2017.1354421.

- y Bordignon, F. (2018). Towards the 5 star party. Contemporary Italian Politics, 10 (4), 346-362. Disponible en: https://doi.org/10.1080/23248823.2018.1544351.

Chiaramonte A., Emanuele, V., Maggini, N. y Paparo, A. (2018). Populist Success in a Hung Parliament: The 2018 General Election in Italy. South European Society and Politics, 23 (4), 479-501. Disponible en: https://doi.org/10.1080/13608746.2018.1506513.

Chryssogelos, A. (2018). State Transformation and Populism: from the internationalized to the neo-sovereign state? Politics, 40 (1), 1-16. Disponible en: https://doi. org/10.1177/0263395718803830.

Colloca, P. y Corbetta, P. (2015). Beyond Protest Issues and Ideological Inconsistencies in the voters of the Movimento 5 Stelle. En F. Tronconi (ed.). Beppe Grillo's Five Star Movement: Organisation, Communication, Ideology (pp. 195-212). London: Routledge.

Corbetta, P. (2013). Un Web-populismo dal destino incerto. En P. Corbetta y E. Gualmini (eds.). Il Partito di Grillo (pp. 197-214). Bologna: Il Mulino.

- (2017). Paradossi, speranze e disillusioni della democrazia digitale in Italia: la lezione del Movimento 5 Stelle. En P. Corbetta (ed.). Come cambia il partito di Grillo (pp. 62606809). Bologna: Il Mulino.

— , Colloca, P., Cavazza, N. y Rocatto, M. (2018). Lega and Five Star Movement voters: exploring the role of cultural, economic and political bewilderment. Contemporary Italian Politics, 10 (3), 279-293. Disponible en: https://doi.org/10.1080/23248823.20 18.1524678 . 
De Rosa, R. y Quattromani, D. (2019). Ruling Rome with Five Stars. Contemporary Italian Politics, 11 (1), 43-62. Disponible en: https://doi.org/10.1080/23248823.2019.1576999.

Diamanti, I. (2014). The 5 Star Movement: a political laboratory. Contemporary Italian Politics, 6 (1), 4-15. Disponible en: https://doi.org/10.1080/23248823.2014.881016.

Farinelli, A. y Massetti, E. (2015). Inexperienced, leftist, and grassroots democrats: a profile of the Five Star Movement's MPs. Contemporary Italian Politics, 7 (3), 213-31. Disponible en: https://doi.org/10.1080/23248823.2015.1076122.

Franzosi, P., Marone, F. y Salvati, E. (2015). Populism and Euroscepticism in the Italian Five Star Movement. The International Spectator 50 (2), 109-124. Disponible en: https://doi. org/10.1080/03932729.2015.1030273.

Gerbaudo, P. y Screti, F. (2017). Reclaiming Popular Sovereignty: The Vision of the State in the Discourse of Podemos and the Movimento 5 Stelle. Journal of the European Institute for Communication and Culture, 24 (4), 320-335. Disponible en: https://doi.org/10.10 80/13183222.2017.1330089.

Goodhart, D. (2017). The Road to Somewhere: The New Tribes Shaping British Politics. New York: Penguin.

Grillo, B. (2005). Il politico e i suoi lacchè. Beppegrillo.it [blog], 18-09-2005. Disponible en: https://web.archive.org/web/20050920162915/http:/beppegrillo.it:80/. (2011). Comunicato politico numero quarantacinque. Ilblogdellestelle [blog], 11-082011. Disponible en: https://www.ilblogdellestelle.it/2011/08/elezioni_on_lin.html.

— (2013 a). Il M5S non è di destra né di sinistra. Beppegrillo.it [blog], 11-01-2013. Disponible en: https:/www.beppegrillo.it/il-m5s-non-e-di-destra-ne-di-sinistra/.

— (2013 b). Il M5S è populista, ne' di destra, ne' di sinistra \#fieramentepopulista. Beppegrillo.it [blog], 14-12-2013. Disponible en: https://bit.ly/2Z35FtE.

- $(2013$ c). Lettera agli italiani. Beppegrillo.it [blog], 06-02-2013. Disponible en: https:// www.beppegrillo.it/lettera-agli-italiani-di-beppe-grillo/.

(2017). Risposta alle domande frequenti sul Movimento 5 Stelle in Europa. Ilblogdellestelle [blog], 20-01-2017. Disponible en: https://bit.ly/2NpgPU5.

Habermas, J. (1994). Three Normative Models of Democracy. Constellations, 1 (1), 1-10. Disponible en: https://doi.org/10.1111/j.1467-8675.1994.tb00001.x.

Hibbing, J. y Theiss-Morse, E. (2002). Stealth Democracy. Americans' Beliefs in how Government Should Work. Cambridge: Cambridge University Press. Disponible en: https://doi. org/10.1017/CBO9780511613722.

Iacoboni. J. (2018). L’esperimento: inchiesta sul Movimento 5 Stelle. Bari: Laterza.

Istituto Cattaneo (2018). Elezioni Politiche 2018: Le prime analisi sui flussi di voto. Disponible en: https://bit.ly/2YoPDew.

Laclau, E. (2005). La razón populista. Buenos Aires: Fondo de Cultura Económica.

Lanzone, L. y Woods, D. (2015). Riding the Populist Web: Contextualizing the Five Star Movement in Italy. Politics and Governance, 3 (2), 54-64. Disponible en: https://doi. org/10.17645/pag.v3i2.246.

Manin, B. (1987). On Legitimacy and Political Deliberation. Political Theory, 15 (3), 338-368. Disponible en: https://doi.org/10.1177/0090591787015003005. 
Manucci, L. y Amsler, M. (2017). Where the wind blows: Five Star Movement's populism, direct democracy and ideological flexibility. Rivista Italiana Di Scienza Politica, 48 (1), 109-132.

Mastropaolo, A. (2005). La mucca pazza della democrazia: nuove destre, populismo, antipolitica. Torino: Bollati Boringhieri.

Michels, R. (1983). Los partidos politicos. Amorrortu: Buenos Aires.

Morlino, L. y Raniolo F. (2018). Come la crisi económica cambia la democrazia. Bologna: Il Mulino.

Mosca, L. (2014). The Five Star Movement: Exception or Vanguard in Europe? The International Spectator, 49 (1), 36-52. Disponible en: https://doi.org/10.1080/03932729.201 3.875821 .

- y Tronconi, F. (2019). Beyond left and right: the eclectic populism of the Five Star Movement. West European Politics, 42 (6), 1258-1283. Disponible en: https://doi.org/1 $0.1080 / 01402382.2019 .1596691$.

— y Vaccari, C. (2017). La progressiva ibridazione dei repertori comunicativi del Movimento. En P. Corbetta (ed.). Come cambia il Partito di Grillo (pp. 5442-6255). Bologna: Il Mulino.

MoVimento 5 Stelle (2009a). Non Statuto. Disponible en: https://bit.ly/3hV8sOk.

- (2009b). Programma M5S. Disponible en: https://bit.ly/3eqKto5.

- (2009c). Carta di Firenze. Disponible en: https://bit.ly/2VampOs.

- (2013). Codice di comportamiento eletti MoVimento 5 Stelle in Parlamento. Disponible en: https://bit.ly/317H0H3.

- (2017a). Statuto dell'associazione denominate "MoVimento 5 Stelle». Disponible en: https://go.aws/3dlM4tS.

- (2017b). Codice Ético. Disponible en: https://go.aws/2Bscz3z.

— (2018a). Programma Nazionale. Disponible en: https://www.movimento5stelle.it/ programma/download.html.

- (2018b). Tutti i risultati delle parlamentarie del MoVimento 5 Selle. Disponible en: https://bit.ly/317YVNH.

Mudde, C. (2004). The Populist Zeitgeist. Government and Opposition, 39 (4), 541-563. Disponible en: https://doi.org/10.1111/j.1477-7053.2004.00135.x.

Musso, M. y Maccaferri, M. (2018). At the origins of the political discourse of the 5-Star Movement (M5S): Internet, direct democracy and the "future of the past». Internet Histories, 2 (1-2), 98-120. Disponible en: https://doi.org/10.1080/24701475.2018.14 57295.

Natale, P. (2014). The birth, early history, and explosive growth of the Five Star Movement. Contemporary Italian Politics, 6 (1), 16-36. Disponible en: https://doi.org/10.1080/232 48823.2014.886418.

Natale, S. y Ballatore, A. (2014). The Web will kill them all: new media, digital utopia, and political struggle in the Italian 5-star Movement. Media, Culture, and Society, 36 (1), 105-121. Disponible en: https://doi.org/10.1177/0163443713511902.

Orsina, G. (2019). Genealogy of a Populist Uprising. Italy: 1979-2019. The International Spectator, 54 (2), 50-66. Disponible en: https://doi.org/10.1080/03932729.2019.1603 896. 
Pasquino, G. (2019). The State of the Italian Republic. Contemporary Italian Politics, 11 (2), 195-204. Disponible en: https://doi.org/10.1080/23248823.2019.1585684.

— y Valbruzzi, M. (2013). Post-electoral politics in Italy: institutional problems and political perspectives. Journal of Modern Italian Studies, 18 (4), 466-484. Disponible en: https://doi.org/10.1080/1354571X.2013.810805.

Pedrazzani, A. y Pinto, L. (2013). Gli elettori del Movimento 5 Stelle. En P. Corbetta y E. Gualmini (eds). Il Partito di Grillo (pp. 89-122). Bologna: Il Mulino.

- (2017). Dove pesca la rete del Movimento: le basi sociali del suo voto. En P. Corbetta (ed.). Come cambia il Partito di Grillo (pp. 3334-3514). Bologna: Il Mulino.

Pirro, A. L. (2018). The Polyvalent Populism of the 5 Star Movement. Journal of Contemporary European Studies, 26 (4), 443-458. Disponible en: https://doi.org/10.1080/14782804. 2018.1519484.

Pitkin, H. (1985). El concepto de representación. Madrid: Centro de Estudios Constitucionales.

Ruano, J. M. (2010). Contra la participación: discurso y realidad de las experiencias de participación ciudadana. Política y Sociedad, 47 (3), 93-108.

Sartori, G. (1999). En defensa de la representación política. Claves de Razón Práctica, 91, 2-6.

Setta, S. (2005). L'Uomo Qualunque. Bari: Laterza.

Stanley, B. (2008). The Thin Ideology of Populism. Journal of Political Ideologies, 13 (1), 95-110. Disponible en: https://doi.org/10.1080/13569310701822289.

Tarchi, M. (2014). Italia Populista: Dal Qualunquismo a Beppe Grillo. Bologna: Il Mulino.

Tronconi, F. (2013). Da dove arrivano i voti del Movimento 5 Stelle? Il Mulino 2, 356-363.

- (2015). Conclusions: The Organisational and Ideological Roots of the Electoral Success. En F. Tronconi (ed.). Beppe Grillo's Five Star Movement: Organisation, Communication, Ideology (pp. 213-230). London: Routledge. Disponible en: https://doi. org/10.4324/9781315569062.

(2018). The Italian Five Star Movement during the Crisis: Towards Normalisation? South European Society and Politics, 23 (1), 163-80. Disponible en: https://doi.org/10.1 080/13608746.2018.1428889.

Urbinati, N. (2019). Me the People: How Populism Transforms Democracy. Cambridge: Harvard University Press. Disponible en: https://doi.org/10.2307/j.ctvk12sz4.

Vignati, R. (2013). Beppe Grillo: dalla Tv ai palasport, dal blog al Movimento. En P. Corbetta y E. Gualmini (eds.). Il Partito di Grillo (pp. 29-63). Bologna: Il Mulino.

- (2017). Dai Comuni al Parlamento: il Movimento entra nelle istituzioni. En P. Corbetta (ed.). Come cambia il partito di Grillo (pp. 270-1317). Bologna: Il Mulino.

Vittori, D. (2017). Podemos and the Five-star Movement: populist, nationalist or what? Contemporary Italian Politics, 9 (2), 142-161. Disponible en: https://doi.org/10.1080/2 3248823.2017.1339935. 